13

\title{
Разработка и исследование автоэмиссионной среды для автокатодов мобильных силовых СВЧ приборов
}

\author{
(C) В.А. Беспалов, ${ }^{1}$ Э.А. Ильичев, ${ }^{1}$ С.В. Куклев, ${ }^{2}$ А.Е. Кулешов, ${ }^{1}$ Р.М. Набиев, ${ }^{1}$ Н.Н. Патюков, ${ }^{1}$ Г.Н. Петрухин, ${ }^{1}$ \\ Г.С. Рычков, ${ }^{1}$ Д.С. Соколов, ${ }^{2}$ Е.Г. Теверовская, ${ }^{1}$ Е.Ю. Шелюхин ${ }^{1}$ \\ ${ }^{1}$ Национальный исследовательский университет „Московский институт электронной техники“, \\ 124498 Зеленоград, Москва, Россия \\ ${ }^{2}$ Общество с ограниченной ответственностью „МЭЛЗ ФЭУ“, \\ 124460 Зеленоград, Москва, Россия \\ e-mail: edil44@mail.ru
}

(Поступило в Редакцию 23 ноября 2016 г. В окончательной редакции 25 июля 2017 г.)

Предложены и экспериментально исследованы автоэмиссионные среды, выполненные на основе гетероструктуры кремний/алмаз с массивами кремниевых микроострий на гетерогранице. Архитектура гетероструктур оптимизирована для применений в качестве активной среды автокатодов мобильных силовых СВЧ приборов.

DOI: $10.21883 /$ JTF.2018.03.45607.2107

\section{Введение}

Радиационностойкая и термостойкая электронная компонентная база (ЭКБ) для приборов и устройств силовой электроники СВЧ и микроволнового диапазона частот остро востребована широким спектром приборов и технических систем. При реализации маломощных СВЧ приборов предпочтение отдается арсениду галлия и твердым растворам на его основе (GaAs-AlAs, GaAs-InAs), здесь в настоящее время достигнуты значительные успехи [1-3]. Существенные успехи достигнуты и в развитии вакуумной силовой СВЧ и микроволновой электроники, в том числе в таких ее актуальных направлениях, как радиолокация (до $30 \mathrm{GHz}$ ), космическая связь, точная локация объектов в субтера- и терагерцовом диапазонах частот, медицинская диагностика и терапия $(\Delta f=300-700 \mathrm{GHz})$. Однако существующие разработки ЭКБ вакуумной силовой СВЧ электроники не удовлетворяют требованиям по мобильности (времени выхода системы в рабочий режим), габаритам и КПД со стороны целого ряда технических систем $[4,5]$.

\section{Выбор базовых материалов и физических эффектов}

Оценки предельных параметров приборов, выполненных на основе различных материалов, позволяют получить шкалу сравнительной эффективности их использования в разработках ЭКБ для силовой СВЧ и микроволновой электроники. В табл. 1 представлены параметры нормализованных по отношению к кремнию критериев эффективности различных материалов для ЭКБ СВЧ и субтерагерцового диапазона частот. Оценки получены при использовании значений параметров материалов, представленных в табл. 2, и наиболее эффективным для радиочастотных применений оказывается алмаз. C учетом фактора „технологичности“ материала (линейные размеры подложек, уровень концентраций фоновой примеси, концентрации структурных дефектов и глубоких энергетических центров) представленная выше шкала сравнительной эффективности материалов претерпевает поправки, касающиеся алмаза. Предпочтение отдают нитриду галлия $[6,7]$, а при реализации твердотельных маломощных приборов - арсениду галлия и твердым растворам на его основе (GaAs-AlAs, GaAs-InAs).

Перечисленные критерии выбора материалов, основанные на сравнительном анализе их электрофизических свойств и учете уровня развития маршрутных технологий, следует дополнить еще фактором - учетом предельных возможностей физических механизмов, положенных в основу работы приборов. При этом доминирующая роль того или иного физического эффекта при реализации характеристик приборов определяется в значительной степени их конструкцией и функциями. Так, для маломощных устройств, способных работать в диапазоне частот больше $100 \mathrm{GHz}$, наиболее успешными являются разработки приборов, в основе работы которых лежат туннельные эффекты (например, туннельно-резонансные транзисторы и диоды на основе GaAs-AlAs и GaAs-InAs). Им характерна „мультиустойчивость“, позволяющая создать очень компактные конструкции функциональных схем с быстродействием в субтерагерцовом диапазоне частот (генераторы, умножители частоты, среды для динамической памяти и др.). Напротив, при реализации твердотельных силовых СВЧ приборов предпочтение отдают нитриду галлия и его твердым растворам. На $\mathrm{GaN}$ сегодня создана линейка полевых транзисторов, перекрывающих диапазон частот до $80 \mathrm{GHz}$ и мощностей до $180 \mathrm{~W}: 80 \mathrm{GHz}-0.3 \mathrm{~W}$, $4 \mathrm{GHz}-15 \mathrm{~W}, 2.17 \mathrm{GHz}-180 \mathrm{~W}$.

Однако реализовать работу полевых приборов, эффективных в частотном диапазоне свыше $40 \mathrm{GHz}$ с 
Таблица 1. Значения параметров нормализованных критериев эффективности различных материалов

\begin{tabular}{c|c|c|c|c|c}
\hline \multirow{2}{*}{ Материал } & \multicolumn{5}{|c}{ Критерии } \\
\cline { 2 - 6 } & $\mathrm{JM}=\left(E_{c} v_{s} / 2 \pi\right)^{2}$ & $\mathrm{KM}=\lambda\left(v_{s} / \varepsilon\right)^{1 / 2}$ & $\mathrm{BM}=\mu \varepsilon E_{c}^{3}$ & $\mathrm{BH}=\mu E_{c}^{2}$ & $\mathrm{QF} 1=\lambda \mu \varepsilon E_{c}^{3}$ \\
\hline $\mathrm{Si}$ & 1 & 1 & 1 & 1 & 1 \\
$\mathrm{Ge}$ & 0.04 & 0.27 & 0.13 & 0.29 & 0.052 \\
$\mathrm{GaAs}$ & 14.3 & 0.42 & 46 & 227 & 14.1 \\
$\mathrm{SiC}$ & 539 & 3.78 & 1460 & 161 & 2200 \\
$\beta$-GaN & 750 & 2.44 & 26000 & 1630 & 2030 \\
Алмаз & 8043 & 18.84 & & & 210000
\end{tabular}

Таблица 2. Параметры, использованные при расчетах нормализованных критериев эффективности материалов

\begin{tabular}{c|c|c|c|c|c|c}
\hline \multirow{2}{*}{ Материал } & \multicolumn{7}{|c}{ Размерность } \\
\cline { 2 - 7 } & $\mu_{e}, \mathrm{~cm}^{2} / \mathrm{V} \cdot \mathrm{s}$ & $E_{c}, \mathrm{~V} / \mathrm{cm}$ & $v_{s}, \mathrm{~cm} / \mathrm{s}$ & $\lambda, \mathrm{W} / \mathrm{cm} \mathrm{K}$ & $\varepsilon$ & $E_{g}(300 \mathrm{~K}), \mathrm{eV}$ \\
\hline $\mathrm{Si}$ & 1500 & $3 \cdot 10^{5}$ & $10^{7}$ & 1.5 & 11.8 & 1.12 \\
$\mathrm{Ge}$ & 3900 & $10^{5}$ & $6 \cdot 10^{6}$ & 0.6 & 16.0 & 0.67 \\
$\mathrm{GaAs}$ & 8500 & $6 \cdot 10^{5}$ & $1.9 \cdot 10^{7}$ & 0.46 & 12.0 & 1.43 \\
$\beta$-GaN & $1200-2000$ & $3.3 \cdot 10^{6}$ & $2.5 \cdot 10^{7}$ & 2.1 & 9.7 & 3.3 \\
$\mathrm{SiC}$ & $650-1000$ & $3.5 \cdot 10^{6}$ & $2 \cdot 10^{7}$ & $3.7(4 \mathrm{H})$ & 10.0 & $3.23(4 \mathrm{H})$ \\
Алмаз & 2200 & $10^{7}$ & $2.7 \cdot 10^{7}$ & 12.0 & 5.7 & 5.4
\end{tabular}

Примечание. $\mu_{e}-$ подвижность электронов, $E_{c}-$ предельные напряженности электрического поля, $v_{s}-$ скорость насыщения электронов, $\lambda-$ коэффициент теплопроводности, $\varepsilon$ - диэлектрическая проницаемость, $E_{g}$ — ширина запрещенной зоны.

мощностью свыше $10 \mathrm{~W}$, оставаясь при этом в рамках ЭКБ твердотельной электроники, затруднительно даже при использовании вышеуказанных высокоэффективных материалов. Это связано с рядом принципиальных физических и конструкционных ограничений, например с уменьшением коэффициента разветвления (а значит, добротности) при частотах свыше $40 \mathrm{GHz}$ из-за значимости величин входной и паразитной емкостей у силовых твердотельных усилительных приборов. Задачи эти решаются использованием ЭКБ вакуумной эмиссионной СВЧ электроники, в рамках которой приборы (например, клистроны и ЛБВ) с рабочими токами $>1 \mathrm{~A}$ и напряжениями в сотни и тысячи $\mathrm{V}$ способны устойчиво работать при повышенных дозах радиации и в температурном диапазоне от $-100^{\circ} \mathrm{C}$ до $+300^{\circ} \mathrm{C}$. Однако мобильность и КПД таких приборов для выполнения ряда задач недопустимо низки, а энергозатратность и большие габариты затрудняют бортовые применения. Причина заключена в использовании в вакуумных силовых приборах термокатодов в качестве источника электронов. Устранить указанные недостатки можно, заменив термокатоды на сильноточные автокатоды, которые помимо чрезвычайно высокой мобильности (время выхода прибора в рабочий режим) позволяют реализовать монохроматичный электронный пучок, устойчивы к колебаниям температуры, слабо чувствительны к внешней радиации, компактны, обеспечивают экспоненциально высокую крутизну вольт-амперных характеристик. Однако 40-50 лет интенсивной многоплановой работы многочисленных групп исследователей в различных лабораториях мира [8-15] не позволили реализовать сильноточные автокатоды и на их основе приборы с совокупностью перечисленных свойств. Не удалось изготовить стабильные автокатоды на плотности токов более $0.1 \mathrm{~A} / \mathrm{cm}^{2}$ для работы в режиме постоянного тока и более $1 \mathrm{~A} / \mathrm{cm}^{2}$ для работы в импульсном режиме, при полном токе, составляющем хотя бы $\sim 0.1$ А. Типичные величины полных токов реализованных автокатодов, как правило, не превышают десятка миллиампер (10 mA), a pecypc их работы чрезвычайно низок (не более 10-100 h в зависимости от амплитуды тока). Причин тому несколько, а их устранение чрезвычайно сложно. Основные из них:

a) отсутствуют технологии формирования острийных автоэмиссионных сред с малой дисперсией аспектных отношений микроострий массива;

б) недопустимо низок предел текучести исходных материалов;

в) существуют проблемы отвода тепла от наноразмерных микроострий массива;

г) чрезмерно велики $(4-5 \mathrm{eV})$ величины потенциальных барьеров автоэмиссионных микроострий на основе тугоплавких металлов и полупроводников, требующие использования больших рабочих напряжений.

Несложно оценить, что минимально допустимое значение предела текучести для автоэмиссионного острия $\left(\sigma_{\text {edge }}\right)$ превышает величину в $(3-5) \cdot 10^{3} \mathrm{~N} / \mathrm{mm}^{2}$ при диаметре острия $\sim 50 \AA$ и пороговом эффективном электрическом поле в $\sim 10 \mathrm{~V} / \mu \mathrm{m}$. При этом для наиболее часто используемых в электронике материалов с высо- 


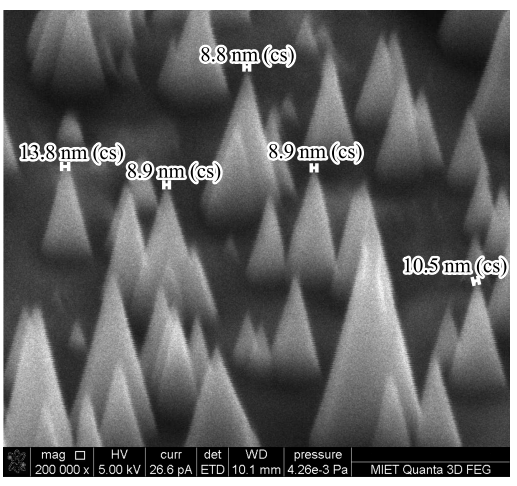

$300 \mathrm{~nm}$

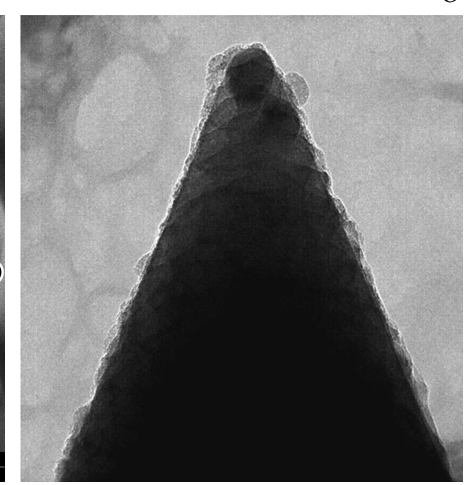

$100 \mathrm{~nm}$

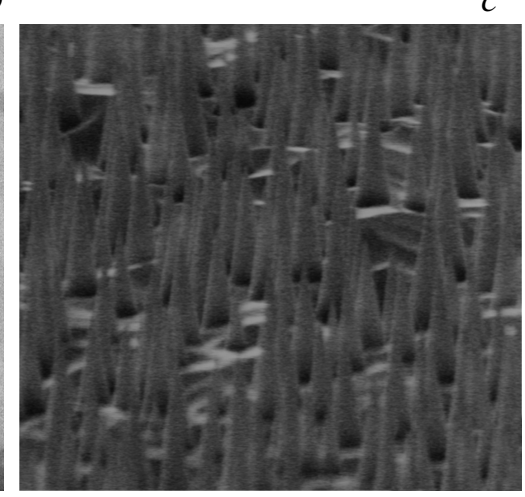

$1 \underline{\mu \mathrm{m}}$

Рис. 1. РЭМ ( $a$ и $c)$ и ПЭМ $(b)$ изображения микроострий, сформированных в подложке монокристаллического кремния.

кими прочностными свойствами, таких как вольфрам и кремний, пределы текучести составляют соответственно $\sigma_{\mathrm{W}} \approx 300 \mathrm{~N} / \mathrm{mm}^{2}$ и $\sigma_{\mathrm{Si}} \approx 10^{3} \mathrm{~N} / \mathrm{mm}^{2}$. При протекании автоэмиссионного тока $\sim 1 \mu \mathrm{A}$ через кремниевое микроострие (nanoSi) высотой $\sim 1 \mu \mathrm{m}$ и диаметром $\sim 100 \AA$ из-за джоулевого тепла происходит его нагрев до температур $1000-1200^{\circ} \mathrm{C}$ (оценки эти подтверждаются в экспериментах), и, как следствие, наблюдается значительная деградация предела текучести. К материалам микроострий, удовлетворяющим требованиям по пределу текучести, относятся алмаз, нитрид галлия и карбид кремния. Алмаз, наиболее эффективный из таких материалов, обладает рядом и других не менее важных преимуществ (табл. 2).

\section{Выбор структуры и конструкции сильноточного автокатода}

Оценки температуры разогрева алмазных микроострий в рабочем режиме дают значения в $\sim 200^{\circ} \mathrm{C}$ при той же геометрии, что и для кремниевых микроострий, а существенно большая величина предела текучести алмаза $\left(\sigma_{\text {diamond }}=3.5 \cdot 10^{3} \mathrm{~N} / \mathrm{mm}^{2}\right)$, с учетом снижения величины пороговых полей автоэмиссии за счет отрицательной энергии сродства к электрону для кристаллографического направления (111), указывают на потенциальную эффективность использования алмаза для сильноточных острийных автокатодов с большим временным ресурсом работы.

Из проблем, названных выше, наиболее сложной для реализации сильноточных острийных автокатодов остается проблема формирования массива наноразмерных микроострий с малой дисперсией аспектных отношений. В [16-18] предложены конструкции микроострийных автокатодов и технологии их изготовления, которые направлены на нейтрализацию отрицательного влияния на режим работы микроострийного автокатода даже значительной дисперсии высот микроострий. Суть этих предложений состоит в том, что автоэмиссионная среда выполняется в виде гетероструктуры подложка $\mathrm{Si} /$ nanoSi/aлмаз, в которой массивы кремниевых микроострий $(\mathrm{nanoSi})$ располагаются на границе раздела кремний/алмаз. В качестве алмазной пленки используется поликристаллическая алмазная пленка (ПАП) слабо легированная акцепторами (бором), осажденная PECVD методом на поверхность с массивами кремниевых микроострий. Толщина ПАП выбирается приблизительно равной средней высоте микроострий массива. Присутствие алмазной пленки приводит к тому, что каждое из кремниевых микроострий заключается в жесткий алмазный каркас, упрочняющий кремниевые микроострия и реализующий эффективный отвод тепла от каждого из них. Для твердотельных вариантов автоэмиссионных диодов (ТАД) поверх поликристаллического алмазного слоя $\left(\mathrm{C}^{*}\right)$ осаждается металлическая пленка с адгезионным подслоем (например, $\mathrm{Cr} / \mathrm{Au}$ ). Таким образом, независимо от высот микроострий массива при приложении к гетероструктуре разности потенциалов (минус на подложке) поле вблизи каждого из микроострий определяется приложенной к структуре разностью потенциалов, толщиной алмазного слоя и диаметром вершин микроострий. В случае равенства диаметров вершин микроострий это обеспечит для каждого из них (независимо от высот микроострий) одинаковые пороговые автоэмиссионные условия. Остается единственное требование реализовать автоэмиссионный массив с микроостриями, имеющими малую дисперсию диаметров вершин. Нами разработана технология, позволяющая реализовать массивы микроострий с малой дисперсией углов при вершинах (рис. 1). В случае острийных автокатодов для вакуумных автоэмиссионных приборов поверх поликристаллического алмазного слоя осаждается туннельнопрозрачная металл-углеродная пленка наноразмерной толщины $(\sim 10 \mathrm{~nm})$. Указанная аморфная пленка получена $[19,20]$ посредством одновременного распыления из плазмотронного и магнетронного источников на холодную подложку углеродного [полифенилметилсилоксан 

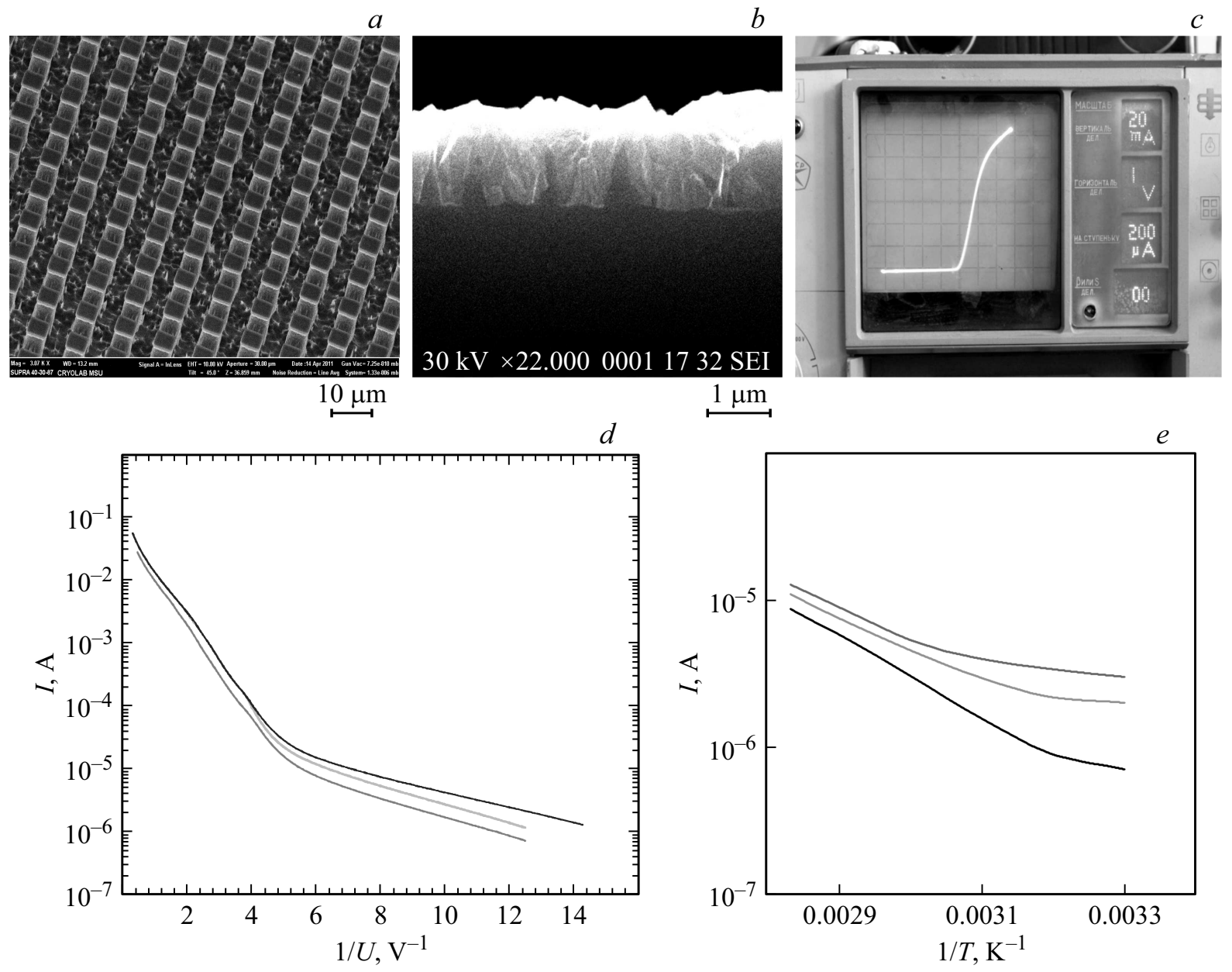

Рис. 2. РЭМ изображения и характеристики твердотельного автоэмиссионного диода (ТАД): $a$ - совокупность диодных автоэмиссионных ячеек (мезаструктур) на поверхности кристалла ТАД; $b$ - поперечное сечение мезаструктуры кристалла ТАД (подложка $\left.\mathrm{Si} / \mathrm{nanoSi} / \mathrm{C}^{*}\right) ; c-$ фотоизображение BAX произвольной диодной автоэмиссионной ячейки (мезаструктуры) ТАД; $d-$ ВАХ произвольной диодной автоэмиссионной ячейки ТАД в „фаулеровских“ координатах в режиме „прямого“ смещения; $e-$ температурная зависимость тока ячейки ТАД в режиме „обратного смещения“ $\left(U_{\text {r.b. }}=9 \mathrm{~V}\right)$ для произвольных трех ячеек кристалла.

$\left.\left(\mathrm{C}_{2} \mathrm{H}_{5}\right)_{3} \mathrm{SiO}\left(\mathrm{CH}_{3} \mathrm{C}_{6} \mathrm{H}_{5} \mathrm{SiO}\right)_{3} \mathrm{Si}\left(\mathrm{CH}_{3}\right)_{3}\right]$ и металлического (молибден) материалов. При такой архитектуре автоэмиссионной среды автокатода на основе гетероструктуры подложка $\mathrm{Si} / \mathrm{nanoSi} / \mathrm{C}^{*} /(\mathrm{Mo}: \mathrm{C}: \mathrm{Si})$, возникшая разность электрических потенциалов между микроостриями различной высоты „снимается“ (компенсируется) протеканием тока по проводящей композитной пленке Mo : C : Si, так что она по всей поверхности автокатода будет находиться под одним потенциалом. Таким образом, у подавляющего большинства микроострий поле вблизи их вершин независимо от высоты микроострий будет определяться приложенной разностью потенциалов, толщиной ПАП и диаметрами вершин микроострий. В плоских приборных конструкциях при таком подходе в жертву, безусловно, приносится однородность поля в пространстве между катодом и анодом, что приведет к ухудшению монохроматичности состава пучка электронов. Однако для сильноточных применений это, как правило, не столь существенно.

\section{Результаты экспериментальных исследований}

В экспериментальных исследованиях образцов автоэмиссионной среды с архитектурой подложка $\mathrm{Si} / \mathrm{nanoSi}$ площадью $1 \times 1 \mathrm{~mm}$, установлено, что при эмиссии электронов в вакуум максимальный автоэмиссионный ток не превышает 50-100 $\mu \mathrm{A}$. И это несмотря на то, что на указанной площади находится до $\sim(1-5) \cdot 10^{4}$ микроострий, а из каждого отдельного микроострия экспериментально удается снять автоэмиссионный ток в пределах $\sim 0.7-1.2 \mu \mathrm{A}$. Таким образом, наблюдается значительное (более чем в 100 раз) расхождение ожидаемых и реализуемых величин полных токов. При исследованиях твердотельного автоэмиссионного диода $[16,17]$ с автокатодом на основе гетероструктуры подложка $\mathrm{Si} / \mathrm{nanoSi} / \mathrm{C}^{*} / \mathrm{Cr} / \mathrm{Au}$ (рис. $2, a, b$ ), в которой выполнены автоэмиссионные ячейки в виде мезаструктур площадью $0.25 \mathrm{~mm}^{2}$ с расположенными на них массивами крем- 
ниевых микроострий, покрытых поликристаллической алмазной пленкой $\left(\mathrm{C}^{*}\right)$ толщиной $\sim 0.5-0.8 \mu \mathrm{m}$, удается достичь автоэмиссионных токов в $\sim 100-120 \mathrm{~mA}$ (т.е. на три порядка больших) и реализовать плотности тока в $50 \mathrm{~A} / \mathrm{cm}^{2}$. Без использования специальных мер для отвода от кристалла тепла ограничения по току с одной мезаструктуры (автоэмиссионной ячейки) на основе гетероструктуры подложка $\mathrm{Si} / \mathrm{nanoSi} / \mathrm{C}^{*} / \mathrm{Cr} / \mathrm{Au}$ наступали $\mathrm{c} \sim 100 \mathrm{~mA}$ (рис. $2, c$ ). На кристалле размером в $1 \mathrm{~cm}^{2}$ расположено до $\sim 50$ таких автоэмиссионных ячеек (мезаструктур). Исследования показали, что ВАХ каждой из автоэмиссионных ячеек в режиме прямого смещения „спрямляется“ в координатах Фаулера-Нордгейма (рис. $2, d$ ) и в диапазоне $300-400 \mathrm{~K}$ не зависит от температуры. Характер ВАХ в режиме обратного смещения (рис. 2,e) определяется глубокими энергетическими центрами с энергией активации $\sim 0.6 \mathrm{eV}$.

Для прямых экспериментальных исследований степени однородности автоэмиссии электронов в вакуум с поверхности автокатодов большой площади нами разработана конструкция корпуса макета вакуумного автоэмиссионного диода, позволяющая в режиме „оn line“ наблюдать автоэмиссию с любого участка поверхности автокатода [21]. На рис. 3 представлена схема конструкции исследуемого макета вакуумного автоэмиссионного диода. Его автокатод 3 имел 2-сторонний кольцевой контакт по периферии к тыльной стороне подложки. Внешний диаметр пластины автокатода составлял $24.5 \mathrm{~mm}$, расстояние между анодами 6, 7 и автокатодом 3 составляло $\sim 0.8 \mathrm{~mm}$. Анод был выполнен в виде катодолюминесцентного экрана на основе $\mathrm{ZnS} / \mathrm{Cr}$, расположенного на волоконно-оптическом стекле, обеспечивающем вывод оптического изображения видимого диапазона (картины катодолюминесценции вещества анода-экрана) из корпуса с пространственным разрешением в $\sim 50 \mu \mathrm{m}$.

Измерению степени однородности автоэмиссии в режиме постоянного тока с поверхности автокатодов большой площади подлежали четыре типа экспериментальных образцов, отличающихся архитектурой структуры автокатода. Специальных мер для отвода „джоулева“ тепла от автокатода и анода-экрана не предпринималось. У образцов первого типа (подложка $\mathrm{Si} / \mathrm{nanoSi}$ ) поверхность автокатода выполнена в виде совокупности мезаструктур с массивами кремниевых микроострий, углы при вершинах которых в пределах пластины составляли $\sim 17-19^{\circ}$. В образцах второго типа автокатод выполнен на основе гетероструктуры подложка $\mathrm{Si} /$ nanoSi/(Mo: C: $\mathrm{Si})$, углы при вершинах микроострий которой в пределах пластины составляли $\sim 19-21^{\circ}$. Образцы третьего типа имели автокатод на основе гетероструктуры подложка $\mathrm{Si} / \mathrm{nanoSi} / \mathrm{C}^{*}$, а автокатод образцов четвертого типа был выполнен на основе гетерструктуры подложка $\mathrm{Si} /$ nanoSi/C* $/(\mathrm{Mo}: \mathrm{C}: \mathrm{Si})$. На лицевой поверхности образцов всех четырех типов была выполнена (рис. $2, a)$ совокупность мезаструктур ( 50 pсs на кристалле автокатода) с площадью каждой из них

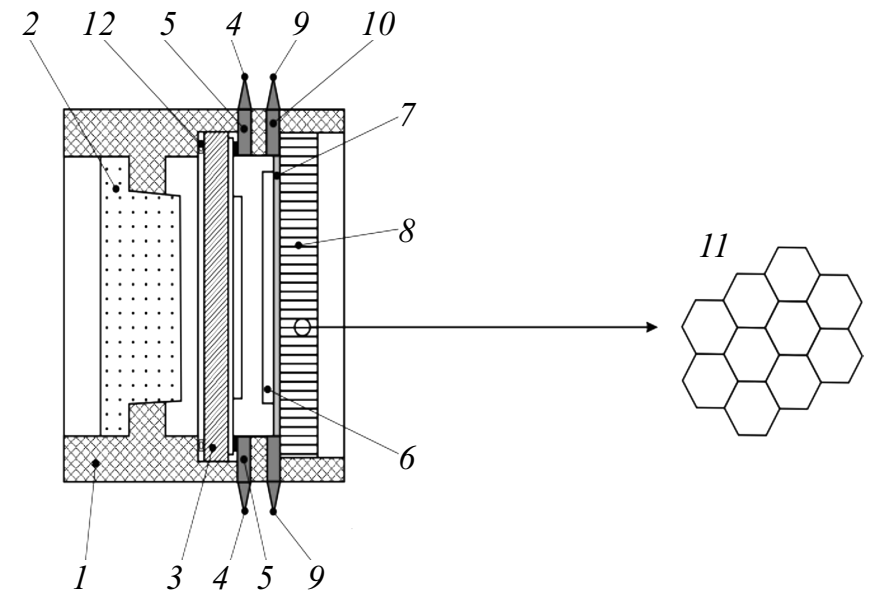

Рис. 3. Схематическое изображение макета вакуумного автоэмиссионного диода (ВАД), позволяющего наблюдать степень однородности автоэмиссии с поверхности автокатода большой площади в режиме „on line“ (1 - вакуумно-плотный металлокерамический корпус, 2 - входное окно, 3 - автокатод, 4, 9 - проводящие электроды, 5, 10, 12 - контакты кольцевые, 6,7 - анод-экран, 8 - волоконно-оптическое стекло (ВОС), 11 - фрагмент ВОС).

$0.5 \times 0.5 \mathrm{~mm}$, а массивы кремниевых микроострий располагались на поверхности кремниевых мезаструктур.

Результаты измерения образцов первого типа (подложка $\mathrm{Si} /$ nanoSi) практически не отличались от результатов, полученных ранее в процессе многочисленных измерений тестовых автоэмиссионных сред с массивами кремниевых микроострий той же и несколько большей $(1 \times 1 \mathrm{~mm})$ площади. Эффективные пороговые поля автоэмиссии здесь составляли $\sim 5.5 \mathrm{~V} / \mu \mathrm{m}$, а максимальные токи, снимаемые с автокатодов указанной выше площади, не превышали 100-200 $\mu$ А. При этом ВАХ вакуумных автоэмиссионных диодов с автокатодами первого типа крайне нестабильны, сопровождались значительным уровнем токового шума, рабочий ресурс диодов не превышал 5-15 min (имела место интенсивная деградация автоэмиссионного тока в течение первой минуты и монотонная - на последующем отрезке времени). Визуализация (по катодолюминесценции) области прихода электронов на анод-экран из $\mathrm{ZnS}$ показало „блуждающий“ характер автоэмиссии электронов с поверхности автокатодов первого типа. Повторное включение диодов первого типа не воспроизводило ни порогов включения диода, ни места локализации процесса автоэмиссии, ни функциональный вид предыдущей ВАХ.

На рис. 4 представлены интенсивность автоэмиссионного тока и картина его координатной визуализации на аноде-экране для образцов с автокатодами второго типа (подложка $\mathrm{Si} /$ nanoSi/(Mo : C : Si)). Как и в автоэмиссионных диодах с автокатодами первого типа, здесь наблюдается автоэмиссия лишь из ограниченного числа локальных областей поверхности пластины автокатода. Однако динамика включения и выключения вакуумного диода с 


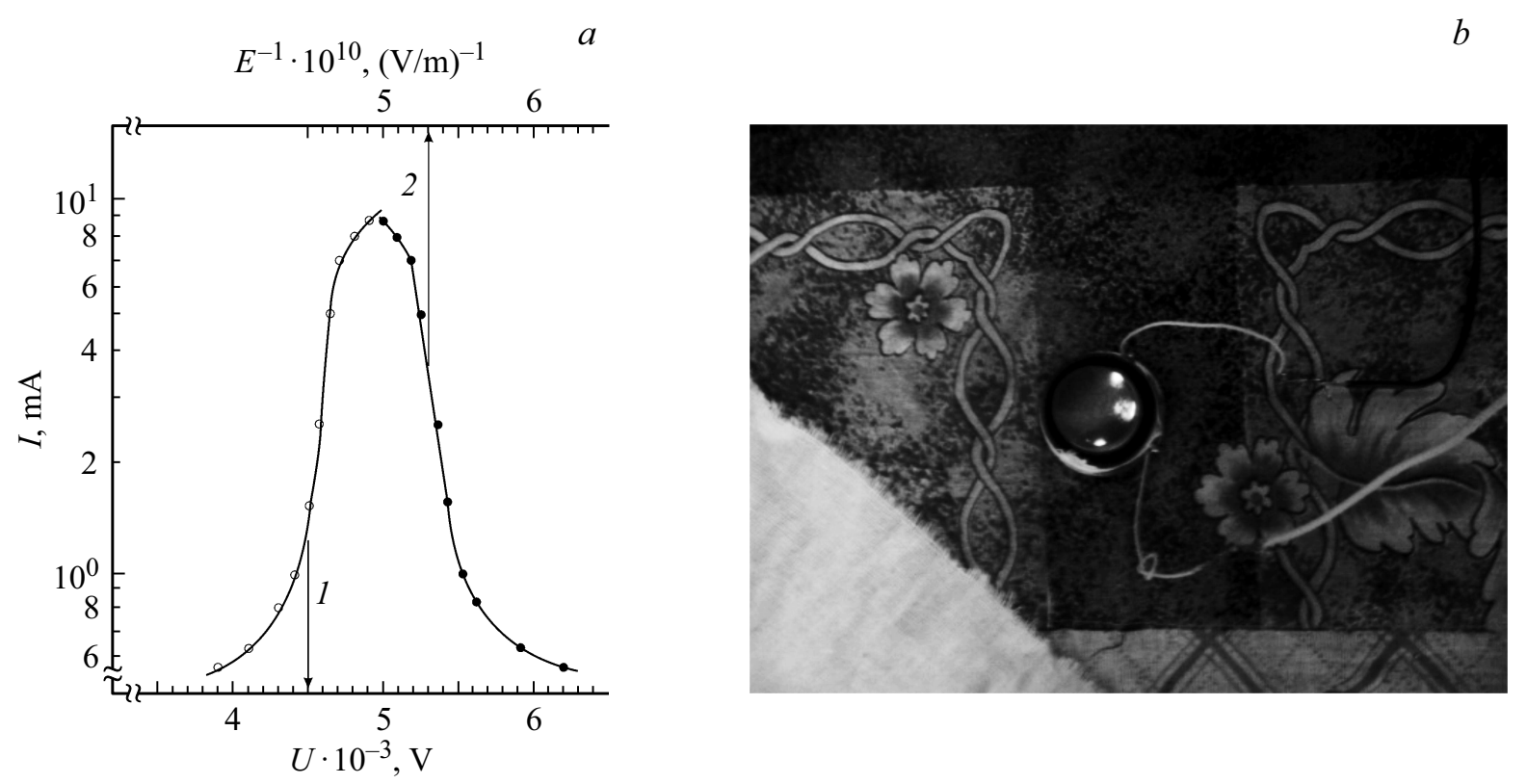

Рис. 4. Характеристики образцов ВАД с автокатодами второго типа (подложка $\mathrm{Si} / \mathrm{nanoSi} /(\mathrm{Mo}: \mathrm{C}: \mathrm{Si})): a-\mathrm{BAX}$ образцов вакуумных автоэмиссионных диодов в „полулогарифмических“ координатах (1) и в координатах Фаулера-Нордгейма (2); $b$ - фотоизображение в режиме „оn line“ картины катодолюминесценции активного вещества анода-экрана, визуализирующей координаты эмиссии с локальных областей автокатода.

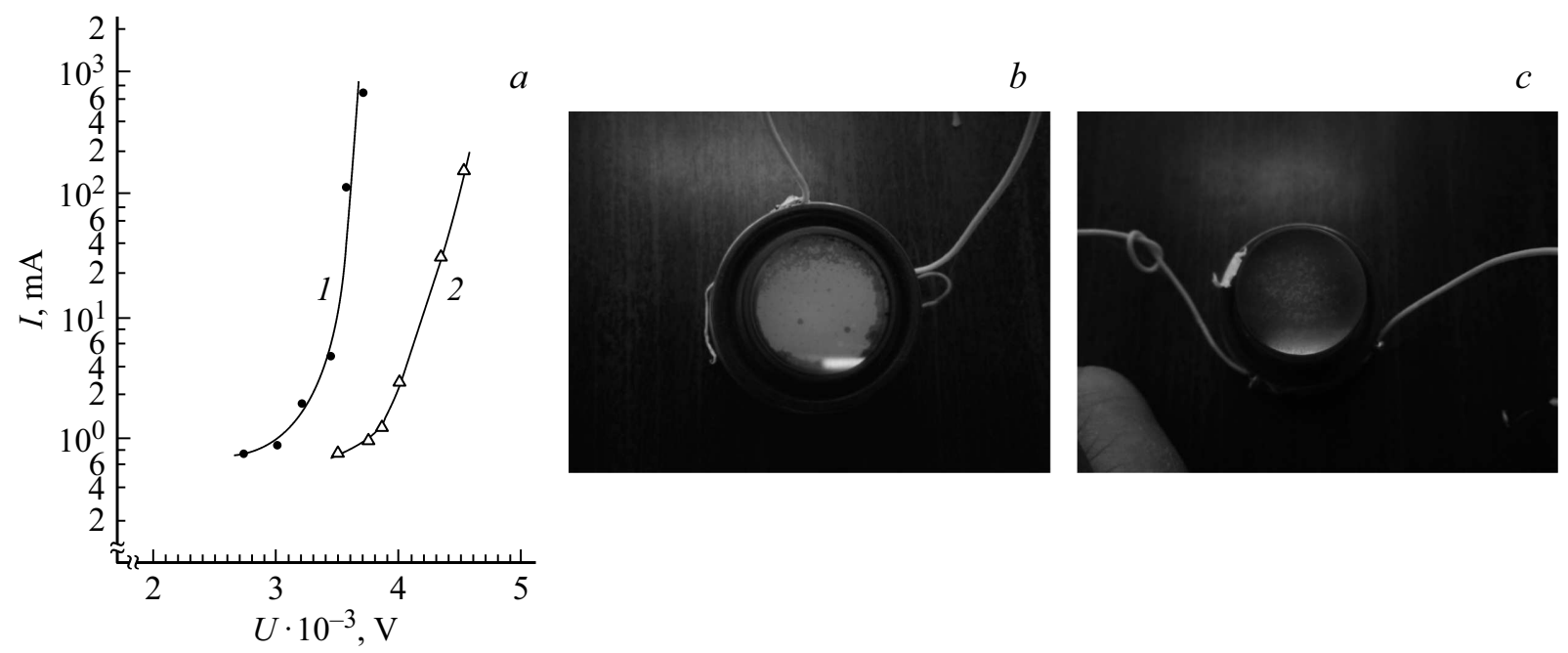

Рис. 5. Характеристики образцов ВАД с автокатодами третьего (подложка $\mathrm{Si} / \mathrm{nanoSi}^{*} \mathrm{C}^{*}$ ) и четвертого (подложка $\left.\mathrm{Si} / \mathrm{nanoSi} / \mathrm{C}^{*} /(\mathrm{Mo}: \mathrm{C}: \mathrm{Si})\right)$ типов: $a-\mathrm{BAX}$ образцов вакуумных автоэмиссионных диодов третьего $(2)$ и четвертого $(1)$ типов; $b$ - фотоизображение в режиме „оn line“ картины катодолюминесценции активного вещества анода-экрана, визуализирующей координаты эмиссии с поверхности автокатода образцов третьего (2) типа; $c$ - фотоизображение в режиме „оп line“ картины катодолюминесценции активного вещества анода-экрана, визуализирующей координаты эмиссии с поверхности автокатода образцов четвертого (1) типа.

автокатодами второго типа совершенно иная. Повторные включения диода воспроизводят пороговые характеристики, функциональный вид ВАХ и координаты эмитирующих электроны локальных областей автокатода. Отсутствует явление краткосрочной деградации ВАХ, а токи в максимуме уже достигают величин 7-9 mA. Обработка ВАX в координатах Фаулера-Нордгейма указывает на наличие участка спрямления BAX в диапазоне токов
1-7 mА. Обработка ВАХ в приближении сильного поля с использованием функциональной зависимости

$$
j=\frac{q^{2} V^{2}}{E_{m} b_{0} 8 \pi^{2} \hbar} \exp \left[-\frac{4 b_{0} \sqrt{2 m}}{3 q \hbar} \cdot \frac{E_{m}^{1.5}}{V}\right]
$$

и в соответствии с представлениями, развитыми в [22] с учетом геометрии микрострий (рис. 1), позволяет 
$a$
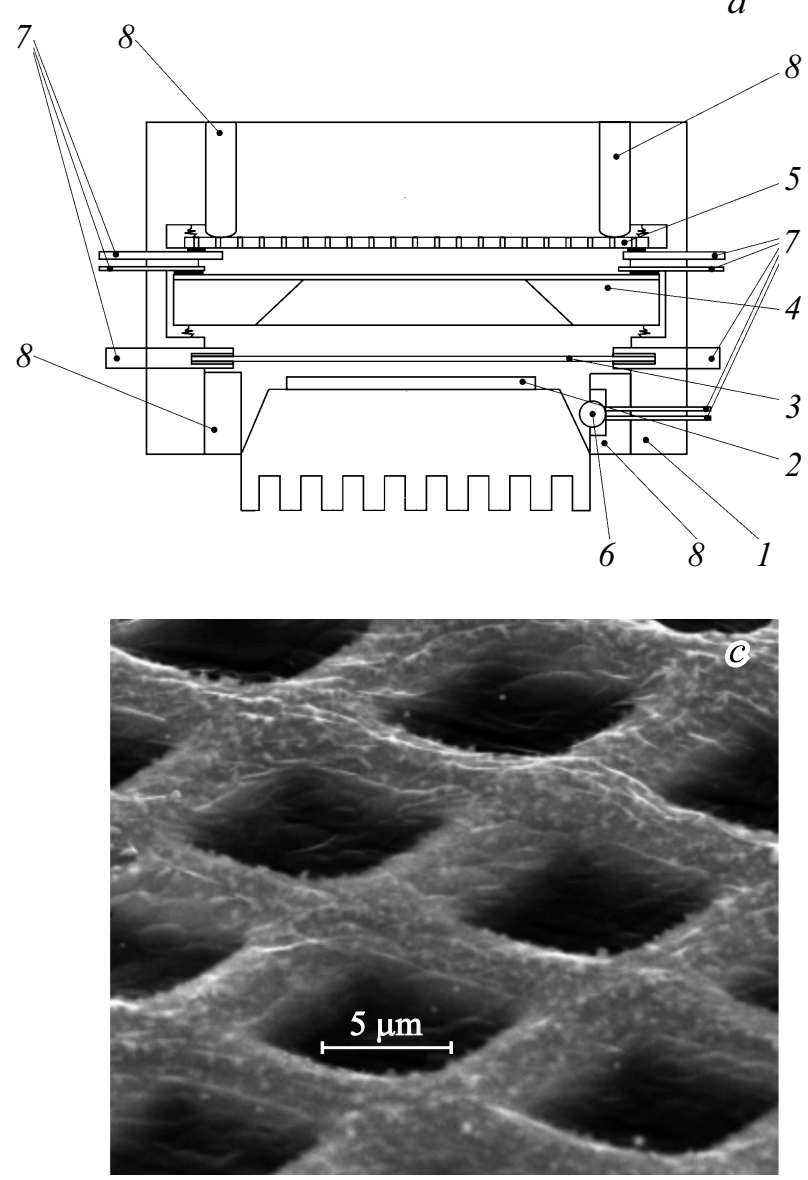
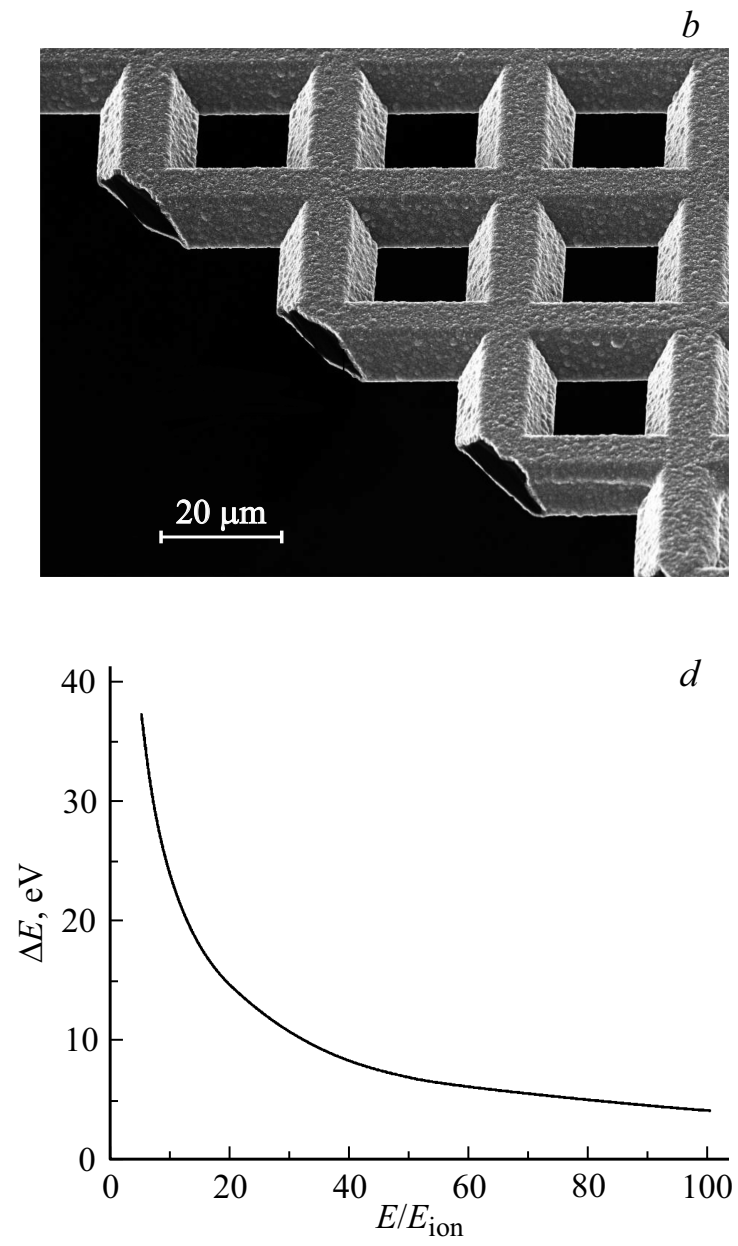

Рис. 6. Комбинированный эмиссионный катод: $a-$ схематическое изображение: 1 - вакуумно-плотный корпус устройства, 2 - острийный автокатод, 3 - вытягивающий электроны электрод, 4 - умножитель-концентратор потока электронов, $5-$ управляющий электрод (управляющая сетка), 6 - геттер, 7 - электрические контакты к перечисленным элементам, 8 изолирующие кольца; $b-$ РЭМ изображение фрагмента умножителя-концентратора потока электронов с активным слоем из ПАП; $c-$ РЭМ изображение графенового электрода; $d-$ энергетические потери электронов в графеновом электроде.

оценить энергию барьера для выхода электронов в вакуум в $\sim 1.9 \mathrm{eV}$.

Здесь введены следующие обозначения: $E_{m}$ - энергетическая величина барьера, $b_{0}-$ средний диаметр вершины микроострия, $V$ - потенциал относительно микроострия в точке, найденной с учетом условия обострения поля, $q$ - элементарный заряд, $\hbar-$ постоянная Планка, $m$ - масса электрона).

Вплоть до токов $~ 6 \mathrm{~mA}$ величина электрического тока растет сверхлинейно, а при токах, больших $7 \mathrm{~mA}$, наблюдается его сублинейный рост. Деградация ВАХ образцов второго типа не имеет места вплоть до подачи на автоэмиссионный диод предельно допустимых напряжений $(\sim 5 \mathrm{kV})$, при которых реализуется межэлектродный пробой по поверхности корпуса автоэмиссионного диода. Картина визуализации посредством катодолюминесценции области прихода эмитируемых электронов на люминесцирующий анод-экран указывает на стабильный локальный характер автоэмиссии электронов с поверхности автокатода второго типа. При этом участку спрямления BAX в координатах Фаулера-Нордгейма соответствует сверхлинейный рост яркости пятна изображения на аноде-экране (для токов 1-7 mA).

Результаты измерений ВАХ образца третьего типа (подложка $\mathrm{Si} /$ nanoSi/C ${ }^{*}$ представлены на рис. 5, a (кривая 2), а на рис. 5,b дана картина визуализации координат его автоэмиссионного тока на аноде-экране. В диодах этого типа также не удается достичь однородного свечения всей площади анода-экрана. При достижении пороговой величины автоэмиссии $(\sim 5 \mathrm{~V} / \mu \mathrm{m})$ наблюдается сверхлинейный характер роста полного автоэмиссионного тока от напряжения на вакуумном автоэмиссионном диоде. При этом, судя по картине визуализации тока, автоэмиссия электронов начинается с периферии поверхности автокатода близ кольцевого электрода контакта к периферии пластины. Расположение области эмитирующих электроны микроострий на поверхности автокатода имеет ярко выраженную 
радиальную симметрию и при повышении напряжения область, эмитирующая электроны, проявляет тенденцию к расширению в радиальном направлении к центру пластины автокатода. Однако выйти на „фаулеровский“ участок BAX и достичь токов насыщения в образцах третьего типа не удается. При токах, больших $\sim 150 \mathrm{~mA}$, поверхность высокоомного анода-экрана $(\mathrm{ZnS})$ начинает выгорать (при этом на излучающих свет участках анодаэкрана выделяется мощность $\sim 1-2 \mathrm{~W}$ ).

Результаты измерений экспериментальных образцов с автокатодами четвертого типа, выполненными в виде гетероструктуры подложка $\mathrm{Si} /$ nanoSi/C* $/(\mathrm{Mo}: \mathrm{C}: \mathrm{Si})$, указывают на существенно более высокую однородность процесса автоэмиссии с поверхности образца. Здесь с ростом разности потенциалов между катодом и анодомэкраном растет площадь катодолюминесцирующей поверхности (с ростом напряжения она монотонно расширяется в радиальном направлении, захватывая все новые участки от периферии к центру) и экспоненциально растет ток, достигающий $700 \mathrm{~mA}$ при напряжении $\sim 3750 \mathrm{~V}$ (рис. 5, $a$, кривая 1 ). Затем наступает интенсивное разрушение высокоомного (на базе $\mathrm{ZnS}$ ) анода-экрана, в силу чего участка ВАX с „фаулеровским“ характером зависимости достичь здесь также не удается. Напомним, при исследованиях использовался режим постоянного тока, и отсутствовал принудительный отвод тепла с анода-экрана и автокатода. На рис. 5, с видно, что для образца четвертого типа в процессе испытаний выгорание активного вещества анода-экрана происходило по всей поверхности анодаэкрана. Сквозь волоконно-оптическое стекло наблюдались массивы выгорающих на аноде-экране пятен, по геометрии напоминающие упомянутые выше мезаструктуры.

\section{Выводы}

1. Представленные выше результаты экспериментальных исследований позволяют сделать аргументированное заключение о реализации процесса автоэмиссии практически со всей поверхности автокатода (диаметром активной области $\sim 15 \mathrm{~mm}$ ) при использовании архитектуры структуры четвертого типа. При этом близ порога „зажигания“ свечение экрана (а значит, выход автоэлектронов) начинается с поверхности гетероструктурного автокатода близ кольцевого электрода, выполненного на периферии подложки. Пороговое напряжение автоэмиссии составляет $\sim 3300 \mathrm{~V}$ (что соответствует эффективной напряженности электрического поля в $\sim 4.5 \mathrm{~V} / \mu \mathrm{m})$. Выход на автоэмиссию с полной площади автокатода осуществляется при приращении (на фоне значения в $3300 \mathrm{~V}$ ) рабочего напряжения на величину $\sim 50 \mathrm{~V}$. Подчеркнем, обсуждаемая конструкция автоэмиссионного диода использована только для проверки в режиме „on line“ степени однородности автоэмиссии с поверхности автокатодов большой площади. Цель - выбор базовой архитектуры автоэмитирующей среды, а затем и конструкции автокатода. Проверить стойкость автокатода к процессам деградации в обсуждаемой конструкции не представляется возможным из-за непременной деградации высокоомного вещества анода (поликристаллического $\mathrm{ZnS}$ ).

2. Дополнительно облегчить рабочий режим автокатода позволит предложенная нами [21] двухкаскадная схема эмиссионного катодного узла (рис. $6, a)$, согласно которой в конструкции эмиссионного прибора последовательно располагаются собственно автокатод, вытягивающий электрод, умножитель-концентратор потока электронов (УКЭ) и управляющий электрод. В такой конструкции „центр тяжести“ процесса формирования электронного пучка переносится на УКЭ с активным слоем из поликристаллической алмазной пленки. Конструкция УКЭ (рис. 6, $b$ ) позволяет осуществить режим умножения „на отражение“ в конструкции „на прострел“. Это, как показывают измерения, допускает реализацию коэффициента умножения до величин в $50-100$.

3. В качестве материала для вытягивающего 3 и управляющего 5 электродов (рис. 6,a) комбинированного эмиссионного катодного узла в гибридном исполнении могут быть использованы графеновые пленки (рис. 6,c). Наши более ранние исследования [23,24] показали, что коэффициент прозрачности графеновой пленки для электронов с энергией большей $200 \mathrm{eV}$ составляет $\sim 90-95 \%$ (рис. $6, d)$. Столь высокий коэффициент прозрачности графеновых пленок позволяет существенно снизить сеточные токи (в приборах с управляющими металлическими сетками сеточные токи составляют 30-40\% от полного анодного тока).

4. Использование предложенной двухкаскадной конструкции эмиссионного катода в приборах вакуумной сильноточной эмиссионной электроники, работа которых основана на функциональной интеграции автоэмиссии и вторичной эмиссии, позволяет не только облегчить автокатоду условия работы, но и уменьшить время выхода сильноточного катодного узла в рабочий режим с 2-3 min (в случае термокатода) до $\sim 10 \mathrm{~ns}$. Действительно, близко расположенный к собственно автокатоду вытягивающий электрод (3 на рис. $6, a)$ будет в статике задавать максимально возможный токовый режим. Динамика работы прибора (модуляция тока во времени) будет определяться подачей сигнала на управляющий электрод 5, регулирующий поток электронов из резервуара внутренней полости ячейки умножителяконцентратора потока электронов, и значительно удаленный от поверхности автокатода. Это позволяет минимизировать емкость системы и не ограничивает ее широкополосности, которая обеспечивается мобильностью эффектов автоэмиссии $(\sim 1-10 \mathrm{ps})$ и вторичной эмиссии ( $\sim 0.1 \mathrm{~ns})$ электронов, положенных в основу работы комбинированного эмиссионного катода. 


\section{Список литературы}

[1] Ayzenshtat G.I., Yushenko A.Y., Gushchin S.M., Dmitriev D.V. et al. // Semiconductors. 2010. Vol. 44. N 10. P. 1362-1364.

[2] Коколов А.А., Черкашин М.В. // Докл. ТУСУРа. 2011. № 2 (24). Ч. 2. C. 17-23.

[3] Hek A.P. Design, Realization and Test of GaAs-based Monolithic Integrated $X$-band High Power Amplifiers. Eindhoven: Technische Universiteit Eindhoven, 2002. 322 p.

[4] Subramanian $K$. et al. Backgated Diamond Field Tip Array Cathodes for $220 \mathrm{GHr}$ TWT. Vanderbilt University, 2009. Final Report. Under Contract W911NF-08-C-0052.

[5] James B.G. // Microwave Systems News and Commun. Technology. 1986. Vol. 16. N 10. P. 105-118.

[6] Yu M., Ward R., Hovda D.H. et al. // IEEE Microw. Wirel. Co. 2007. Vol. 17. N 12. P. 894-896.

[7] Ma B.Y., Boutros K.S., Hacker J.B., Nagy G. // IEEE MTT-S. 2008. P. $1473-1476$.

[8] Махов В.И. // Электронная промышленность. 1994. № 7-8. C. $93-98$.

[9] Chung B.H., Han S.Y., Choi J.O. // J. Vac. Sci. Technol. B. 2002. Vol. 20 (50). P. 2080-2084.

[10] Wang Z.L., Gao R.P., de Heer W.A., Poncharal P. // Appl. Phys. Lett. 2002. Vol. 80. P. 856-859.

[11] Дюбуа Б.Ч., Королев А.Н. // Электронная техника. Сер. 1. СВЧ-техника. 2011. Вып. 1 (508). С. 5-24.

[12] Ляшенко С.А., Волков А.П., Образцов А.Н. // ЖТФ. 2012. T. 82. Вып. 2. С. $94-98$

[13] Jensen K.L., Yater J.E., Shaw J.L. et al. // J. Appl. Phys. 2010. Vol. 108. P. 044509.

[14] Ha J.K., Chung B.H., Han S.Y. et al. // J. Vac. Sci. Technol. B. 2002. Vol. 20. N 50. P. 2080-2084.

[15] Беспалов В.А., Ильичев Э.А., Кириленко Е.П. и др. // Изв. вузов. Электроника. 2014. № 4 (108). С. 27-35.

[16] Беспалов В.А., Ильичев Э.А., Кулешов А.Е., Мигунов Д.М. и др. // Письма в ЖТФ. 2013. Т. 39. Вып. 4. С. 46-52.

[17] Беспалов В.А., Ильччев Э.А., Кулешов А.Е., Мигунов Д.М. и др. // ЖТФ. 2014. Т. 84. Вып. 10. С. 112-116.

[18] Ильичев Э., Кулешов А., Набиев Р., Петрухин Г. и др. // Электроника НТБ. 2014. Спецвыпуск (00137). С. 143-155.

[19] Горячев А.В., Ильичев Э.А., Кирпиленко Г.Г., Кириленко Е.П., Мигунова Е.С., Петрухин Г.Н., Рычков Г.С., Шелюхин Е.Ю. // 12-я междунар. конф. „Пленки и покрытия2015“. СПб., 2015. С. 219-221.

[20] Belyaev S.N., Kirpilenko G.G., Kirilenko E.P., Goryachev A.V. et al. // J. Surf. Invest. $X$-ray. 2016. Vol. 10. N 4. P. 753-757.

[21] ГК № 14.427.11.0003. Шифр „2013-24-14-426-0001“. НИУ „МИЭТ“. Зеленоград. Руководитель НИР Ильичев Э.А.

[22] Ильичев Э.А., Набиев Р.М., Петрухин Г.Н., Рычков Г.С., Кулешов А.Е., Мигунов Д.М. // Изв. вузов. Электроника. 2011. № 5 (91). С. 18-35.

[23] Ильччев Э.А., Кулешов А.Е., Набиев Р.М., Петрухин Г.Н. и др. // Письма в ЖТФ. 2013. Т. 39. Вып. 18. С. 25-31.

[24] Ильичев Э.А., Кириленко Е.П., Петрухин Г.Н., Рычков Г.С. и др. // Письма в ЖТФ. 2014. Т. 40. Вып. 2. C. $10-15$. 